\title{
An electronic engineering curriculum design based on concept-mapping techniques
}

\author{
S. L. Toral · M. R. Martínez-Torres · F. Barrero • \\ S. Gallardo · M. J. Durán
}

\begin{abstract}
Curriculum design is a concern in European Universities as they face the forthcoming European Higher Education Area (EHEA). This process can be eased by the use of scientific tools such as Concept-Mapping Techniques (CMT) that extract and organize the most relevant information from experts' experience using statistics techniques, and helps a working group to achieve conclusions. This paper presents an empirical exploratory research study related to the application of the CMT to the design of the Electronic Engineering (EE) Degree at the University of Seville, Spain. Considering the Career-space conclusions as the initial point, the main relevant competences were identified in a brainstorming technique. These competences are organized according to their affinity using CMT, establishing and interpreting the main clusters and their relative importance. Finally, a reliability analysis of the concept maps was carried out verifying the correctness of the procedure and validating the results for the curricula adaptation.
\end{abstract}

Keywords Concept mapping · Electronic Engineering · Competences · Curriculum design

\section{Introduction}

The situation of Higher education in Europe is going through a period of transition to the European higher education area (EHEA), which will change the structure of University

This Project has been funded by the Spanish PAFPU ("Plan Andaluz de formación del profesorado universitario"), from the Quality Assurance Agency for Andalucía Unversities, (UCUA).

S. L. Toral $(\bowtie) \cdot$ F. Barrero · S. Gallardo · M. J. Durán

Dpto. De Ingeniería Electrónica, E. S. Ingenieros, Universidad de Sevilla, Avda. Camino de los Descubrmientos s/n, Seville 41092, Spain

e-mail: toral@esi.us.es

M. R. Martínez-Torres

Dpto. De Administración de Empresas y Comercialización e Investigación de Mercados, Esc. Univ. de Estudios Empresanales, Universidad de Sevilla, Avda. San Francisco Javier s/n, Seville 41005, Spain 
degrees by 2010. The initial intentions exposed in the Sorbonne declaration and the bologna Magna Charta Universitatum (Joint declaration on harmonisation of the European Higher Education Area 1998; Joint declaration of the European Ministers of Education 1999) are gradually becoming a reality and the Universities have now the necessity to adapt the educational system to the new situation. This process of convergence implies both structural and methodological changes that aim to promote the mobility and employability, paying attention to individual, academic and labour market needs (Communique of the Conference of European Ministers Responsible for Higher Education 2005). Regarding academic needs, learner-centred approaches are promoted in the EHEA, moving the focus from the teacher to the students, and considering the learner satisfaction outcomes (Toral et al. 2005; Hadjerrouit 2005). In this sense, the learner achievements are defined in terms of competences (Commission of the European Communities 2005), which include the knowledge, skills and attitudes that should be promoted in the students. These competences must be defined in order to achieve lifelong learning and to reinforce cross capacities. Several Universities and working groups are gradually defining both the generic and the specific competences (University of Deusto and University of Groningen 2003; University of Deusto and University of Groningen 2005). Nevertheless, in order to take into account labour needs and to increase the employability, professional profiles must be defined (Career-Space Project 2001a, b) to ease the definition of the proper competences and methodologies. The curriculum design, in the sense of the process of defining and organising content, teaching and learning strategies, has been a dynamic process since its inception, emerging from the previous experiences and needs of the social context in which it is imparted. But nowadays it implies a challenge to reflect on what should be taught and to redefine new educational paradigms. This designing process should be carried out in the framework of the EHEA with the above mentioned restrictions.

In this scenario, the development of scientific tools to guide the curriculum design is becoming urgent and of increasing relevance (Martínez-Torres et al. 2005; Thomson 1997). The concept-mapping technique (CMT) is an easy-to-implement and powerful tool to help in the planning and evaluation stage of a project (Trochim 1989). Probably, the most difficult step in a planning or evaluation project is the first one as everything which follows depends on how well the project is initially conceptualized. Conceptualization in this sense refers to the articulation of thoughts, ideas, or hunches and the representation of these in some objective form. Concept mapping is a type of structured conceptualization based on the participants' previous experience and it guides a working group to extract conclusions, determining the main points to be reinforced when planning a particular project. It has been previously used in appropriate course teaching methodology design (Martínez-Torres et al. 2005), or in primary school and master levels for the purposes of content organization (Thomson 1997; Toral et al. 2006). It has also been specifically used for curriculum design and development (Van Neste-Kenny et al. 1998; The University of Tennessee at Chattanooga 2002). The present study explores the use of CMT as a scientific methodology for designing the curriculum of an Electronic Engineering degree at the University of Seville, Spain.

The starting point for the analysis are the Career Space conclusions (Career-Space Project 2001a, b), which are briefly explained in Sect. 2. Section 3 deals with the conceptmapping theory, describing the different stages and procedures, and applying the CMT for designing the curriculum of an Electronic Engineering degree at the University of Seville, Spain. Results and conclusions from the application of the CMT are also exposed in Sect. 3. In order to validate the procedure, a reliability analysis is included in Sect. 4 , showing a 
comparative analysis with previously published concept-mapping results. Finally, the main conclusions are exposed and discussed in Sect. 5.

\section{Professional profiles}

Career Space is a consortium of nine major European ICT companies (BT, Cisco Systems, IBM Europe, Intel, Microsoft Europe, Nokia, Philips Semiconductors, Siemens AG and Thales). With the support of the European Commission and European Information, Communications and Consumer Electronics Industry (EICTA), and coordinated by International Co-operation Europe Ltd., Career Space has recently set up a project to determine a clear framework for students, education institutions and governments, that describes the roles, skills and competences required by the ICT industry in Europe. In order to achieve the employability promulgated by the EHEA (Joint declaration on harmonisation of the European Higher Education Area 1998; Joint declaration of the European Ministers of Education 1999), the curriculum design must consider this framework in the EE degree.

The Career Space Consortium (CSC) conclusions consider the need for educational innovation to satisfy the ICT requirements for the 21 st century. It is not the CSC intention to establish how to design the curricula, but to provide the University sector with information about the existing needs and to suggest guidelines to reduce the deficiencies in the professional competences. According to CSC conclusions, the ICT graduates need a solid background of technical competences, both in the Engineering and Informatics fields, and a wide systemic perspective. Students need to reinforce teamwork competences and have a real experience in projects where several activities are developed in parallel. Furthermore, learners should have basic knowledge of economy, markets and companies. It is also necessary for the ICT graduates to have interpersonal skills, capacity to solve problems and learn to learn, sharpness to determine the customer and colleague needs and consciousness of the multicultural context. These conclusions are in line with some other related initiatives, like OECD DeSeCo (Rychen and Salganik 2003)

Career Space offers basic profiles representing the main areas with existing and foreseeing formative deficiencies. Eighteen professional profiles have been developed by the CSC (Career-Space Project 2001a, b), describing those strictly related to the ICT sector, but also including some multidisciplinary ones referring to cross-sectors (ICT and management). These competences not derived from the engineering or informatics, but from another disciplines (such as economics, business or social sciences), are becoming even more important than technical skills. Table 1 shows all professional profiles established by the CSC.

Table 1 ICT job profiles

\begin{tabular}{ll}
\hline Radio Frequency (RF) Engineering & Technical Support \\
\hline Digital Design & Product Design \\
Data Communications Engineering & Integration \&Test/Implementation \& Test Engineering \\
Digital Signal Processing Applications Design & Systems Specialist \\
Communications Network Design & ICT Marketing Management \\
Software \& Applications Development & ICT Project Management \\
Software Architecture and Design & Research and Technology Development \\
Multimedia Design & ICT Management \\
IT Business Consultancy & ICT Sales Management \\
\hline
\end{tabular}

Digital Design, Digital Signal Processing, Applications Design and Product Design 
Historically, two main paths have been followed in the ICT curriculum design. These routes have been derived from the electrical engineering and the informatics, leading to different evolutions in University departments. As a consequence, the focus and methodologies are also different even for the solution of the same problems. This study develops a method based on the concept-mapping theory for the EE curriculum design in accordance with the EHEA requirements and considering the CSC recommendations.

\section{EE degree curriculum design using CMT}

A concept map is a method of structured conceptualization that can be used to develop the conceptual framework to guide a process (e.g. curriculum redesign) (Toral et al. 2006; Kolb and Shepherd 1997). This method follows a scientific procedure defined by a sequence of steps (Trochim 1989), and taking into account both quantitative and qualitative feature, such us numerical ratings and participants' previous experiences, respectively. The CMT structures the data using statistical methods that include a multidimensional scaling and clusters analysis, leading to a categorization of the ideas. Furthermore, the different clusters are statistically identified, providing information about their relevance and inter-relationship.

Some other methods are available to create the concept maps, such as CMaps (http:// cmap.ihmc.us), a free application that supports multiple platforms and is available on the Internet.

The CMT as defined by Trochim follows five different stages as defined by Kolb and Shepherd (1997):

1. Selecting and preparing the participants.

2. Brainstorming session (items' selection).

3. Structuring and rating items.

4. Representing items in a concept map (multidimensional scale and cluster analysis).

5. Interpreting the maps.

\section{Selecting and preparing the participants}

The participants forming the working group must have a good knowledge about the EE field, as well as the educational reality of the institution in which the curriculum is going to be implemented. The number of participants is recommended to be between 10 and 20 (Delbecq et al. 1975). An excess in the number of participants will difficult the brainstorming session and the agreement in the final conclusions. Following the above mentioned requirements, 14 participants were selected for the design of the EE curriculum, all of them related in some extent to the Electronic Engineering Department of the University of Seville. Half of the participants were lecturers associated to this department and the other half were old students with some professional relation with the department and currently working in electronic companies. Once the working group was formed, some preparative sessions were organized to collect information before the brainstorming stage. Among the CSC professional profiles shown in Table 1, the working group identified three of them to be covered by the EE: Digital Design, Digital Signal Processing, Applications Design and Product Design. The characteristics of these profiles as appearing in CareerSpace Project $(2001 \mathrm{a}, \mathrm{b})$ were analysed by the participants inside the first CTM stage. Table 2 summarizes tasks and technologies related with them. 
Table 2 Career space profiles related to EE curriculum

\begin{tabular}{|c|c|c|}
\hline Profiles & Tasks & Technologies \\
\hline \multirow[t]{5}{*}{ Digital Design } & $\begin{array}{l}\text { - Participation in the definition of } \\
\text { architectures }\end{array}$ & - Board design, system emulators \\
\hline & $\begin{array}{l}\text { - Translating the digital parts into } \\
\text { circuit diagrams }\end{array}$ & - CMOS circuits, mixed signal circuits \\
\hline & $\begin{array}{l}\text { - Design and development of printed } \\
\text { circuit boards and integrated } \\
\text { circuits }\end{array}$ & - Microprocessors \\
\hline & $\begin{array}{l}\text { - Putting the initial boards into } \\
\text { operation and testing them }\end{array}$ & - Digital Signal Processors \\
\hline & & - Printed Circuit Boards \\
\hline \multirow[t]{5}{*}{$\begin{array}{l}\text { Digital Signal } \\
\text { Processing }\end{array}$} & $\begin{array}{l}\text { - Being up-to-date with the technical } \\
\text { development in this field }\end{array}$ & - Digital Signal Processing \\
\hline & $\begin{array}{l}\text { - Using simulation tools efficiently to } \\
\text { check performance and the } \\
\text { behaviour of the signals }\end{array}$ & - Embedded systems \\
\hline & $\begin{array}{l}\text { - Designing SW for signal processors } \\
\text { and digital filters depending on the } \\
\text { application in Assembler or C. }\end{array}$ & - Real-time applications \\
\hline & - Coding the SW and implementing it. & - Wireless communication technology \\
\hline & & - System simulation technology \\
\hline \multirow{4}{*}{$\begin{array}{l}\text { Applications } \\
\text { Design and Product } \\
\text { Design }\end{array}$} & $\begin{array}{l}\text { - Planning of hardware, both } \\
\text { prototypes and specific parts. }\end{array}$ & - Analog/Digital Circuit Design \\
\hline & $\begin{array}{l}\text { - Design and testing of subsystems } \\
\text { and prototypes }\end{array}$ & - Signal Processing \\
\hline & $\begin{array}{l}\text { - Testing and integration of new } \\
\text { products }\end{array}$ & - High Frequency Planning \\
\hline & & - Analog/Digital Electronics \\
\hline
\end{tabular}

\section{Brainstorming session}

Subsequent brainstorming sessions served to identify and list the relevant items for the EE curriculum design according to the professional profiles previously analysed. The theme of the brainstorming session was the identification of the knowledge and skills deemed important as outcomes of an EE programme of learning taking into account Career Space profiles summarized in Table 2. Participants were informed about Career Space initiative and the profiled related to EE curriculum design in a preparative session of one hour and a half. The brainstorming session took place two days later during another hour and a half. As a result, 98 items, shown in Table 3, were selected based on the agreement of participants.

Structuring and rating items

Once the working participants established the set of items describing the conceptual domain of the brainstorming session, it was necessary to obtain information related to their 
Table 3 List of items selected in the brainstorming sessions

1. Knowledge of the industrial processes for the creation of electronic systems

3. Electromagnetic compatibility: legal regulation, technology

5. Basic electronic instrumentation: multimeters, oscilloscopes

7. Problem solving capacity with Infinite degrees of freedom

9. Signal conditioning

11. Leadership skills

13. Types of signal conditioning

15. Basic analog electronic: elemental components

17. Use of catalogs

19. Hardware description languages: HDL, VHDL

21. Communication protocols

23. Microprocessors

25. Electronic components purchase management

27. Analog filters design and analysis

29. Power devices supply systems

31. Hardware treatment of faulty systems

33. Comparison of alternatives in problem solving

35. Electronic market analysis

37. Technical reports creation

39. Criticism ability

41. Creation of marketing documents

43. PCB design: CAD

45. Electronic engineering history

47. Industrial processes control application

49. Electrical systems energetic efficiency

51. Acoustic and audio principles

53. Analog-digital interface

55. Knowledge of nanosystems

57. Thermal calculations

59. Digital processing

61. Electrical isolation and security

63. Reliability

65. Quality test and control

67. Budget elaboration

69. Offers, quotes

71. Top-down, down-top design

73. Industrial oriented communications

75. Wireless technologies

77. Aerospatiale electronics

79. Analysis and selection of electronic technologies for specific applications
2. Promotion of the initiative

4. Design according to quality legal regulation

6. Supplying systems

8. Sensors and actuators

10. Network quality analysis instrumentation

12. Basic digital electronics

14. $\mathrm{C}++$ programming

16. Electronic Engineering knowledge from Internet accessible data base

18. Web handling

20. Microprocessors interfaces

22. Field buses

24. Video and audio processing

26. Digital filters design and analysis

28. Design with cost and resources restrictions

30. Equipments protection

32. Circuit faults identification

34. Passive components

36. English language

38. Teamwork skills

40. Project oral presentation

42. Inverse engineering

44. Test procedures design

46. Power switches

48. Renewable energy applications

50. Energy conversion

52. Local market environment knowledge

54. Microsystems

56. Optoelectronics

58. Automotive electronics

60. Analog processing

62. Applicable regulation

64. Maintenance

66. Creativity

68. Communication skills

70. Selling psychology

72. Project management abilities

74. Domotic

76. Tasks planning

78. Systems integration

80. Range of applicability of different electronic technologies 
Table 3 continued

$\begin{array}{ll}\begin{array}{l}\text { 81. Instrumentation software: LabView } \\ \text { 83. Reusability }\end{array} & \begin{array}{l}\text { 82. Multimedia software: Java } \\ \text { 84. Synthesis skills }\end{array} \\ \begin{array}{ll}\text { 85. Aesthetic design } & \text { 86. Electromechanic drive technology } \\ \text { 87. Materials' technology related to electronic } & \text { 88. PCB manufacturing technologies } \\ \text { applications } & \\ \text { 89. Integrated circuits manufacturing technologies } & \text { 90. Communication technologies } \\ \text { 91. Radiofrequency } & \text { 92. I+D+I management } \\ \text { 93. Ageing and fatigue of systems and components } & \text { 94. Defense technologies } \\ \text { 95. Co-simulation } & \text { 96. Prototyping } \\ \text { 97. Operative systems knowledge and use } & \text { 98. Ofimatic software knowledge and use }\end{array}\end{array}$

relative importance and inter-item relationship. Both tasks constitute the stage of items' rating and structuring in the concept mapping development process.

The former task was performed by the participants scoring the 98 items following a Likert scale (Likert 1932), where 1 indicates minimum contribution and 7 indicates maximum contribution to the aims of the CSC. It must be noted that the value "null contribution" makes no sense in the questionnaire since all the items where identified as relevant competences in the brainstorming stage. Consequently, all items contribute in some extent to the EE curriculum. All participants filled the questionnaire individually, rating the 98 items of Table 3 just using their previous experience and their personal criteria.

The inter-item relationship task was also carried out individually by the participants, classifying the items in several groups according to their affinity using their own criteria. The subsequent statistical analysis will summarize theses criteria. The statistical analysis guarantees that all opinions are treated in the same way, with no opinions prevailing against others. The classification of the items and the number of groups is based on participants' previous experience. A similarity matrix $S$ of $n \times n$ dimension, with $n=98$, is obtained as follows: the value of each $(i, j)$ element is equal to 1 if the $i$ th and $j$ th items are grouped together, and is equal to 0 otherwise. Each item can only be placed in one group. Participants were encouraged to be imaginative, i.e., not to include all items in a group or form as many groups as items. The total similarity matrix $T$ of $n \times n$ dimension is obtained adding all the similarity matrices $\left(S_{n \times n}\right)$.

\section{Concept-map representation}

The representation of the items in a concept map implies a double data processing. Firstly, a multidimensional scaling is carried out obtaining a two-dimensional representation of the 98 items of Table 3 . As a result, the map includes a set of rating points whose distance is inversely proportional to their affinity. Secondly, a cluster analysis is developed to group the items into significative groups. The cluster map provides several rated blocks to be used in the curriculum design.

The multidimensional scale is a multivariate statistic technique that considers the total similarity matrix $T_{n \times n}$ and represents the distance of the matrix items in a $p$-dimensional space $(p<\mathrm{N}+1)$. The distances in the $p$-dimensional space must be similar to the distances in the original $n$-dimensional space (Fahrmeir and Hamerle 1984). The most common approach to determine the coordinates of the map points is an iterative process usually 
referred to as the Shepard-Krustal algorithm (Fahrmeir and Hamerle 1984). The multidimensional scaling generates a map with the set of items selected in the brainstorming stage, and based on the similarity matrix obtained from the classification task.

In order to develop the multidimensional scaling, the results obtained from each participants' classification are placed into a similarity matrix $S_{n \times n}$, that has 98 rows and columns in the present analysis. The number of similarity matrices is equal to 14 (the number of participants) in this study, and all the matrix values are zero or one. A one indicates that a participant classifies the row item and the column item into the same group. To the contrary, a zero shows that both items (row and column) were not included in the same group.

Consequently, diagonal elements are one since an item is always self-grouped. Next, all 14 individual similarity matrices are added to create a group matrix (total matrix $T_{n \times n}$ ). The dimension of this matrix is again $n \times n(n=98)$, but now the meaning of the matrix values indicates how many participants grouped these items (row and column ones) together. Regardless of how the participants grouped the items, a high value in the total matrix shows a high correlation between these items. Similarly to the individual matrices, the diagonal elements of the global matrix have a value equal to the number of participants (i.e. 14). To the contrary, a low value in the global matrix indicates that the row and column items were rarely grouped together, so they are not conceptually related. For each item, the mean value of the participants' scoring is calculated.

The multidimensional scaling analyst must fix the number of dimensions to represent the set of points. A one-dimensional solution represents all points in a single line, while a two-dimensional solution places the points on a plane. It is theoretically possible to use up to $n$ dimensions, but solutions with more than three dimensions are complex to interpret. Consequently, CMT uses two-dimensional representations providing easy-to-interpret results at the expenses of losing information.

In the case study, the multidimensional scaling provides the point map shown in Fig. 1. Each point represents one of the 98 items exposed in Table 3, and the distance between points indicates the affinity of the two items/points. Those points that are close have a high affinity in their competences (knowledge, skills or attitudes) while those which are far from each other have a low conceptual affinity. Notice that the statistical processing summarizes the personal criteria of participants. The point map is just a two-dimensional projection of the distances derived from the total similarity matrices $\left(T_{n \times n}\right)$ obtained from participants

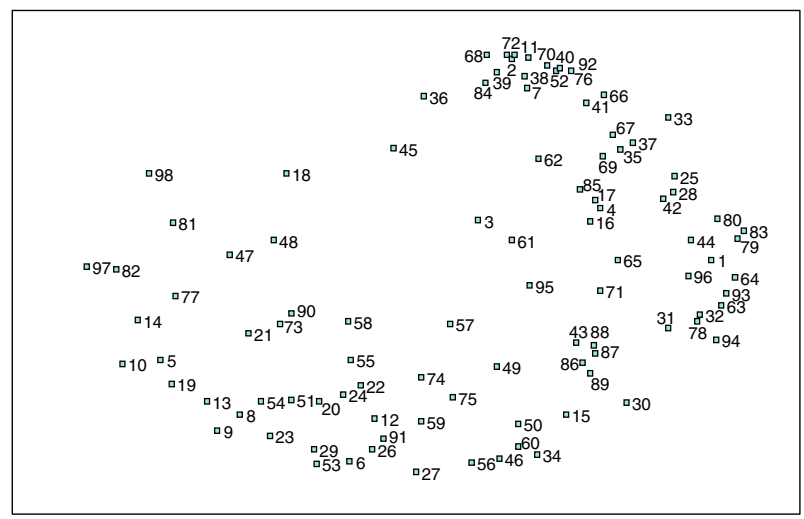

Fig. 1 Point map obtained from the multidimensional scaling 
classifications. Obviously, the final result is an approximation of the original distances due to the two-dimensional restriction. The multidimensional scaling aims to minimize the objective function related with the sum of the square distances between the points.

Figure 2 shows the rating point map that includes the items' scoring made by the participants. Consequently, Fig. 2 exposes the relative importance of each item with regard to its contribution to the EE programme. In the upper left-hand corner of the figure, the correspondence between layers and numerical Likert values is shown.

Once the two-dimensional representation has been obtained, it is necessary to classify the items in homogeneous groups to define the inputs for the curriculum design tool. This categorization is carried out with cluster analysis based on the Ward's algorithm.

The cluster analysis organizes the information coming from the multidimensional scaling, not from the similarity matrix (Everitt 1993), and the Ward's algorithm was used for the cluster analysis because it offers more sensitive and more easy-to-interpret solutions than other estimations (Ward 1963). Initially, the cluster analysis considered each item as a cluster, thus obtaining a solution with $n$ clusters (98 in the present study). Ward's algorithm combines two clusters for each level of analysis, obtaining all items into just one cluster. A key issue is the determination of the number of clusters to be used in the final solution. Therefore, the different solutions must be carefully examined to identify the ones that make sense. As a rule, it is preferred to err by excess than by defect, i.e. a higher number of clusters is better assumed than the inclusion of heterogeneous concepts inside one cluster.

The obtained result is shown in Fig. 3 that includes the point map together with the different groups highlighted by the cluster analysis. It must be noted that this analysis needs to determine a priori the number of clusters/groups. The procedure to reach the proper number of clusters is to begin with a high number of groups (say 20 or 22) and gradually reduce this number until a cluster includes two groups with no affinity. This procedure leads to a final number of 18 clusters in the present study and guarantees that a group does not include heterogeneous concepts.

The final analysis requires an average score for each participant and for each cluster, generating a rating cluster map. In the case study, the inclusion of the scores for each cluster leads to the representation of Fig. 4 where the score ranges according to Likert scale are shown in the bottom-left corner.

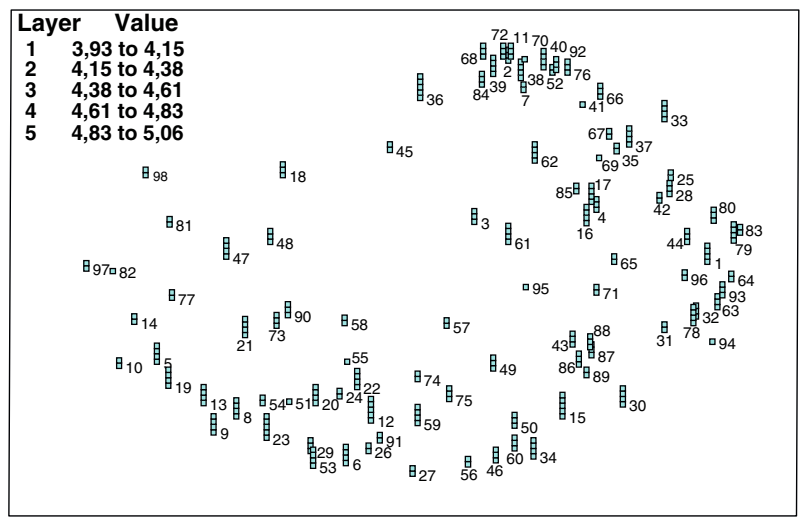

Fig. 2 Rating point map obtained from the multidimensional scaling 


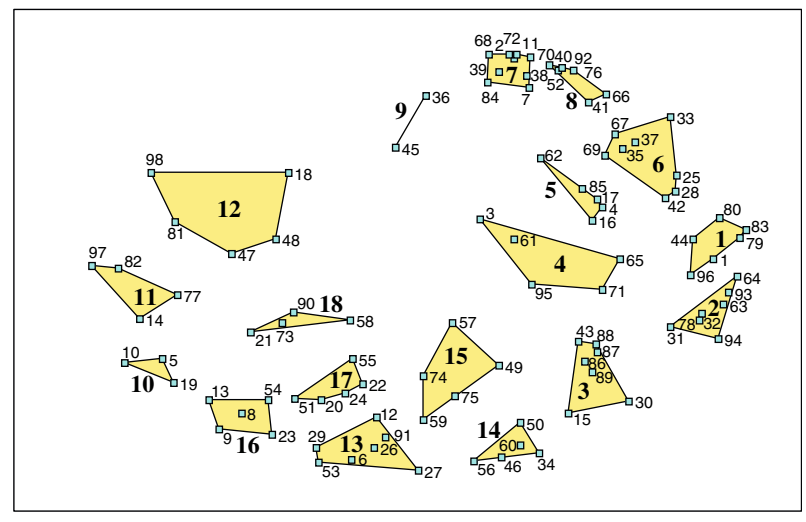

Fig. 3 Cluster map

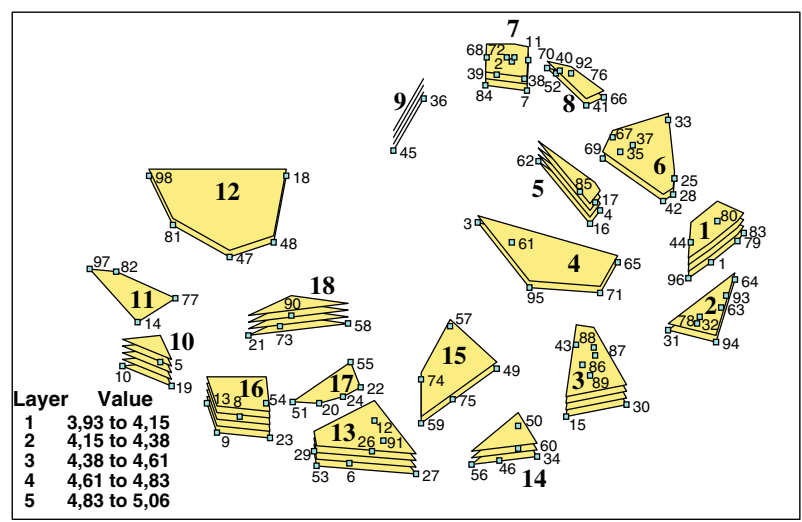

Fig. 4 Rating cluster map

Interpretation of the maps

In order to interpret the maps, a final workgroup was organized. Generally, the results derived from the cluster analysis are more difficult to interpret than those from the multidimensional scale. The cluster analysis is seen as an indicator. At times, one would like to "visually arrange" the clusters into sensitive parts so that the multidimensional space could be interpreted more easily. The key is to maintain the integrity of the multidimensional scale results by achieving a solution that will not allow the clusters to overlap. A consensus of the names given to the different clusters must be reached, using as a starting point those names given to the groups by the participants. Table 4 collects the assigned names of the 18 clusters and their classification into 6 regions, as represented in Fig. 5.

The first region, located in the right side of Fig. 5, refers to the Electronic Engineering design, and includes 6 clusters:

- Cluster 1: Production procedures. It refers to the knowledge of EE production; processes for electronic devices manufacturing, test procedure design and selection of adequate technologies according to the application area. 
Table 4 Cluster and region names

\begin{tabular}{lll}
\hline Región 1: Electronic Engineering design & Cluster 1 & Production procedures \\
& Cluster 2 & Fault diagnosis/solving \\
& Cluster 3 & Manufacturing technologies and design \\
& Cluster 4 & Industrial processes for electronic design \\
& Cluster 5 & Legal regulation and standards \\
& Cluster 6 & Electronic project management \\
& Cluster 7 & Personal and instrumental competents \\
Región 2: Cross competences & Cluster 8 & Systemic competences \\
& Cluster 9 & Other competences \\
& Cluster 11 & Programming knowledge \\
Región 3: Programming & Cluster 12 & Informatics applied to electronics \\
& Cluster 10 & Instrumentation \\
Región 4: Electronics instrumentation & Cluster 18 & Industrial communications \\
Región 5: Microprocessors systems & Cluster 16 & Sensors and signal conditioning \\
Región 6: Electronic knowledge & Cluster 17 & Microprocessors systems and applications \\
& Cluster 13 & Basic electronics \\
& Cluster 14 & Power electronics \\
& Cluster 15 & Emerging technologies \\
\hline
\end{tabular}

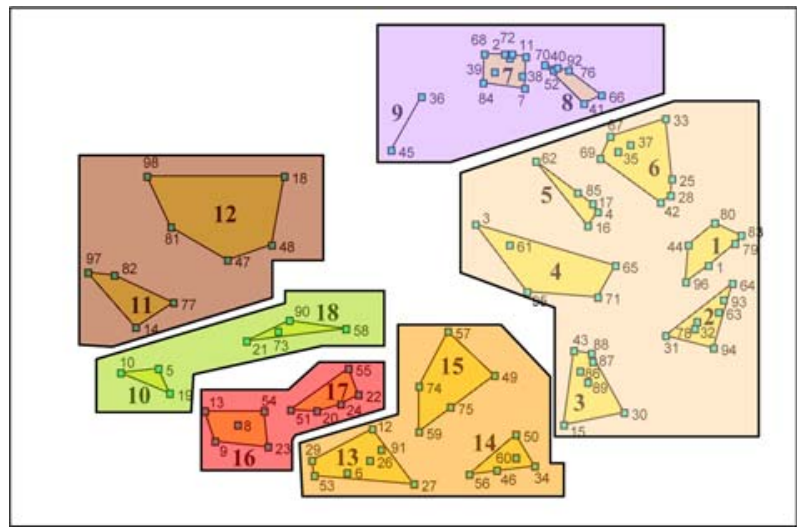

Fig. 5 Regions in the cluster map

- Cluster 2: Fault diagnosis/solving. It includes hardware treatment of faulty devices, circuit fault identification, reliability, maintenance, and ageing and fatigue of systems and components.

- Cluster 3: Manufacturing technologies and design. It groups basic analog electronics and components, PCBs design, devices protection, electromechanic drives technologies, PCBs manufacturing design, and integrated circuit manufacturing design.

- Cluster 4: Industrial processes for electronic design. Electromagnetic compatibility, electrical isolation and security, top-down down-top design and co-simulation.

- Cluster 5: Legal regulations and standards. It includes the regulations related to the electronics, catalog use and industrial electronics data base knowledge. 
- Cluster 6: Electronic project management: Electronic components purchase management, design with cost and material restrictions, comparison of alternatives in problem solving, electronic market analysis, technical report creation, inverse engineering, budget elaboration and offers.

The second region included in Fig. 5 refers to the Cross Competences. In the design and re-design of University curricula, it is of fundamental importance to take into account the dynamic needs of the society as well as the present and future of the labour market (Communique of the Conference of European Ministers Responsible for Higher Education 2005). These cross competences will allow the future graduate to adapt her/himself to the dynamic circumstances and environments. This region embraces 3 clusters:

- Cluster 7: Inter-personal and instrumental competences. Inter-personal competences are related to the personal expression, criticism and auto-criticism capacities. These competences have a social dimension including personal and teamwork capacities (University of Deusto and University of Groningen 2003, 2005). The instrumental competence include:

- Cognitive abilities: capacity to understand and apply ideas.

- Methodological abilities: time organization, learning strategies, decision making and problem solving.

- Technological abilities: related to the use of software and hardware.

- Language abilities: oral and writing capacities.

- Cluster 8: Systemic competences. It represents a combination of understanding, sensitivity and knowledge that allows considering how the parts of a whole are related among them. This cluster includes the capacity to plan modifications for the global system improvement and for a novel system design. These systemic competences are usually based on instrumental and inter-personal skills.

- Cluster 9: Other competences. It refers to other competences not previously cited, such as the use of languages and general culture knowledge.

The third region that can be found in Fig. 5 focuses on the Programming Knowledge, and groups two clusters:

- Cluster 11: Programming knowledge. It refers to general purpose programming knowledge such as C, C++, Java or Operative Systems.

- Cluster 12: Informatics applied to electronics. It includes software tools directly related to the electronic design.

The fourth region in Fig. 5 refers to Instrumentation, and groups two different clusters:

- Cluster 10: Instrumentation. Basic electronic instrumentation, multimeters, oscilloscopes, advanced instrumentation, network quality measurement.

- Cluster 18: Industrial communication. Communication technologies, protocols and industry applications, automotive electronics.

The fifth region appearing in Fig. 5 refers to Microprocessors and includes two clusters:

- Cluster 16: Sensors and signal conditioning. Sensors and actuators, different types of signal conditioning. Microprocessors system processing.

- Cluster 17: Microprocessors systems and applications. Microprocessors systems and DSPs. Video and audio processing applications, external interfaces. 
Finally, the sixth region of Fig. 5 considers Basic Electronic knowledge grouping three clusters:

- Cluster 13: Basic electronics. Digital and analog basic electronics, digital and analog filter design, digital-analog interface, radiofrequency, supplying systems.

- Cluster 14: Power electronics. Passive components, power switches, energy conversion.

- Cluster 15: emerging technologies. Advanced digital processing, domotic, wireless technologies, energetic efficiency.

If the cluster map shown in Fig. 4 is analysed, it can be observed that the clusters with lower rating are those with specific electronic content, basically related to instrumentation and industrial communication, microprocessors systems and basic electronics. On the other hand, clusters regarding legal regulations and standards or industrial design and process obtain a higher score. Cross competences and programming competences show lower scores probably because it is assumed that these are skills that the students should receive in previous courses.

\section{Reliability analysis}

A reliability analysis was accomplished to guarantee the obtained results. Traditional reliability theory used in social science research does not properly fit the concept maps because it assumes a correct answer for each test item that is known a priori. Therefore, the individual results for each item are classified as right or wrong. However, this procedure does not apply to concept maps where the answer for an item cannot be considered in simple terms (correct or incorrect). Because of this, the data matrix structure is inverted (compared to traditional theory) for the reliability assessment, i.e. the participants are placed in columns and the items (or pair of items) are located in rows. The reliability assessment focuses on consistency via the group of theoretically homogeneous participants. From this approach, it becomes useful to consider the reliability of the similarity matrix or map instead of the individual statements reliability (Trochim 1993). The key product of the CMT is the 2-D concept map; consequently, the reliability assessment efforts are focused on the central stages of the analysis: development and representation. In the study published by Trochim (1993), the concept-map reliability was tested by six coefficients that can be estimated form the available data on any concept map project. These coefficients were defined and estimated for 38 concept map projects. The results show that a concept map process can be considered reliable according to standards generally recognized for acceptance reliability levels.

All the six CMT reliability indicators used by Trochim (1993) are considered for the reliability assessment. Table 5 summarizes the results for the concept map of the present study, including the mean value for each coefficient. In order to establish usual ranges for the different coefficients, the results from Trochim (1993) are also included in Table 6.

It can be observed that a high degree of reliability is found in the proposed concept map since all indicators are included inside usual ranges:

(1) The Individual-to-Individual Sort Reliability, $r_{\text {II }}$, which correlates each participant's binary sort matrix $S_{n \times n}$ for each pair of individuals and explains how the sorts are correlated for the different participants in the development of the concept map, is 
Table 5 Reliability results

\begin{tabular}{ll}
\hline Individual-to-Individual reliability $\left(r_{\mathrm{II}}\right)$ & Result: 0.79282 \\
Individual-to-Total matrix reliability $\left(r_{\mathrm{IT}}\right)$ & Result: 0.93803 \\
Individual-to-map reliability $\left(r_{\mathrm{IM}}\right)$ & Result: 0.88931 \\
Average intersort reliability $\left(r_{\mathrm{RR}}\right)$ & Result: 0.74244 \\
Split-Half reliabilities $\left(r_{\mathrm{SHM}}\right.$ and $\left.r_{\mathrm{SHT}}\right)$ & Result (Similarity matrices): 0.93027 \\
& Result (Distance matrices): 0.86613 \\
\hline
\end{tabular}

Table 6 Descriptive statistics for reliability estimates

\begin{tabular}{llllllr}
\hline & $r_{\mathrm{II}}$ & $r_{\mathrm{IT}}$ & $r_{\mathrm{IM}}$ & $r_{\mathrm{RR}}$ & $r_{\mathrm{SHT}}$ & $r_{\mathrm{SHM}}$ \\
\hline Number of projects & 33 & 33 & 33 & 37 & 33 & 33 \\
Mean & 0.81507 & 0.92965 & 0.86371 & 0.78374 & 0.83330 & 0.55172 \\
Median & 0.82060 & 0.93070 & 0.86280 & 0.82120 & 0.84888 & 0.55881 \\
Minimum & 0.67040 & 0.88230 & 0.74030 & 0.42700 & 0.72493 & 0.25948 \\
Maximum & 0.93400 & 0.97370 & 0.95490 & 0.93540 & 0.93269 & 0.90722 \\
Standard deviation & 0.07016 & 0.02207 & 0.04771 & 0.12125 & 0.05485 & 0.15579 \\
\hline
\end{tabular}

identified by calculating the average of the correlations and by applying the Spearman-Brown Prophecy formula (Nunnally 1978):

$$
r_{k k}=\frac{k \bar{r}_{i j}}{1+(k-1) \bar{r}_{i j}}
$$

where $r_{i j}$, correlation estimated from data; $K=N / n$, being $N$ the total sample size and $n$ the sample size on which $r_{i j}$ is based; $r_{\mathrm{kk}}$, reliability estimated according to the SpearmanBrown Prophecy formula. This coefficient presents a value of 0.79282 which is below the mean value of Table 5 but above the minimum value of 0.6704 . Consequently, the obtained individual-to-individual sort reliability is acceptable.

(2) The Individual-to-Total Matrix Reliability, $r_{\text {IT }}$, which correlates each participant's binary sort matrix $S_{n \times n}$ with the total matrix $T_{n \times n}$ and determines how the sorts carried out by each participant correlates with all sorts, is evaluated averaging these correlations and applying the Spearman-Brown Prophecy formula. The obtained value for this coefficient is 0.93803 . This value is above the mean value of Table 5 indicating satisfactory results for this type of reliability.

(3) The Individual-to-Map Reliability, $r_{\mathrm{IM}}$, which correlates each participant's binary sort $S_{n \times n}$ with the Euclidean matrix distances $D_{n \times n}$, is obtained taking the average of these correlations and applying the Spearman-Brown Prophecy formula. Table 4 shows a value of 0.88931 for this type of reliability. It can be considered a satisfactory result since it is between the acceptable range and above the mean value (0.86371) shown in Table 5.

(4) The Average Intersort Reliability, $r_{\mathrm{RR}}$, which calculates the correlation among the scores of each pair of participants, is obtained using the average of the correlation and the Spearman-Brown Prophecy formula, leading to a value of 0.74244 . Consequently, the concept map scores are reliable since this value is close to the mean value. 
(5) Finally, the Split-Half Reliabilities, $r_{\mathrm{SHT}}$ and $r_{\mathrm{SHM}}$, were also evaluated. The sort from each project is divided into two halves, calculating the concept maps for each group. The total matrices $T_{\mathrm{A}}$ and $T_{\mathrm{B}}$ are correlated, and the Spearman-Brown Prophecy formula is applied to obtain $r_{\mathrm{SHT}}$. The Euclidean distances were correlated between all pairs of points on the two maps $\mathrm{D}_{\mathrm{A}}$ and $\mathrm{D}_{\mathrm{B}}$, and the Spearman-Brown correction was applied to achieve $r_{\mathrm{SHM}}$. The similarity matrix result $\left(r_{\mathrm{SHT}}\right)$ and the distance matrix result $\left(r_{\mathrm{SHM}}\right)$ are 0.93027 and 0.86613 , respectively. Both values are significantly above the mean values $(0.8333$ and 0.55172 , respectively) indicating acceptable values.

All in all, the proposed concept map is reliable since all different coefficients are between Trochim's range showing acceptable values.

\section{Limitations of the study}

The main limitation of the study is that results are strongly dependent on the participants' selection process. During brainstorming session and during the rating and classification tasks, participants are requested to apply their personal experience. According to Duncan and Biddle (1974), participants presage would have a strong influence in the obtained results. Nevertheless, this effect is modulated by the statistical processing of data. Obtained results will summarize the group opinion. Obviously, these results will be more valuable if participants are coming from different sectors of activity (teaching, industry, students, ...).

\section{Conclusions}

The new higher educational framework provided by the convergence to the EHEA needs the development of tools to be used for curriculum design. The focus of attention of EHEA is placed on the development of skills and competences, and consequently, new curriculum proposals should be aligned with the qualification profiles and needs requested by a particular sector of activity. In order to achieve employability, professional profiles must be determined and competences must be defined according to the desired graduate characteristics. The curriculum design should be guided by a scientific method to guarantee the reliability of results, like that proposed in this paper which is based on CMT defined by Trochim. The proposed method establishes a set of stages to be followed by a working group and is based on multivariate statistics. The CMT proves to be useful to classify the proposed competences (items) into meaningful groups and regions. Furthermore, it provides the relative importance of each group, guiding the curriculum design process and easing the consensus inside a working group. The main advantage of concept mapping is that results bring together several points of view and different criteria from experts in the analyzed topic. The statistical analysis avoids that some opinions could prevail against other. Consequently, results are strongly conditioned by a good selection of the participants. In spite of the exploratory nature of the study, a reliability analysis has been developed to guarantee the generalisability of results. The proposed concept map is fully reliable. This reliability has been verified calculating the six Trochim's indicators, which are inside acceptable ranges defined by previous investigations. Moreover, this technique could be extended to other areas different to the proposed in this paper. 
Acknowledgements Funding for this work was provided by the Spanish PAFPU ("Plan Andaluz de formación del profesorado universitario"), from the Quality Assurance Agency for Andalucía Unversities, (UCUA). We appreciate the continued and enthusiastic support of our project officer, $\mathrm{M}^{\mathrm{a}}$ Teresa Padilla.

\section{References}

Career-Space Project. (2001a). Generic ICT skills profiles. Office for Official Publications of the European Communities.

Career-Space Project. (2001b). Directrices para el desarrollo curricular. Nuevos currículos de TIC para el siglo XXI: el diseño de la educación del mañana. Office for Official Publications of the European Communities.

Commission of the European Communities. (2005). Recommendation of the European Parliament and of the Council on Key Competences for Lifelong Learning, Brussels.

Communiqué of the Conference of European Ministers Responsible for Higher Education. (2005). The European Higher Education Area -Achieving the Goals', Bergen.

Delbecq, A. L., Van de Ven, A. H., \& Gustafson, D. H. (1975). Group techniques for program planning: A guide to nominal group and DELPHI processes. Glenville, IL: Scott Foresman and Company.

Duncan, M. J., \& Biddle, B.J. (1974). The study of teaching. New York, NY: Holt, Rhinehart and Winston.

Everitt, B. S. (1993). Cluster analysis. Halsted Press.

Fahrmeir, L., \& Hamerle, A. (1984). Multivariate Statistische Verfahren. Berlin: De Gruyter.

Hadjerrouit,An electronic engineering curriculum design S. (2005). Learner-centered web-based instruction in software engineering. IEEE Transactions on Education, 48(1), 99-104.

Joint Declaration on Harmonisation of the European Higher Education Area: May 25 ${ }^{\text {th }}$ 1998, by the four Ministers in charge for France, Germany, Italy and the United Kingdom, Paris, the Sorbonne.

Joint Declaration of the European Ministers of Education: June 19 ${ }^{\text {th }}$, 1999, 'The European Higher Education Area', Bologna.

Kolb, D. G., \& Shepherd, D. M. (1997). Concept mapping organizational cultures. Journal of Management Inquiry, 6(4), 282-295.

Likert, R. (1932). A technique for the measurement of attitudes. Archives of Psychology, 22(140), 1-55.

Martínez-Torres, M. R., Barrero, F., Toral, S. L., \& Gallardo, S. (2005). A digital signal processing teaching methodology using concept-mapping techniques. IEEE Transactions on Education, 48(3), 422-429.

Nunnally, J. C. (1978). Psychometric theory (2nd ed.). New York: McGraw Hill.

Rychen, D. S., \& Salganik, L. H. (Eds.). (2003). Key competencies for a successful life and a wellfunctioning society. Göttingen: Hogrefe \& Huber Publishers.

The University of Tennessee at Chattanooga. (2002). Concept Mapping and curriculum. Grayson H. Walker Teaching Resource Center. Retrieved May 20, 2007 from http://www.utc.edu/Administration/WalkerTeachingResourceCenter/FacultyDevelopment/ConceptMa pping/index.html.

Thomson, C. J. (1997). Concept mapping as a means of evaluating primary school technology programmes. International Journal of Technology and Design Education, 7, 97-110.

Toral, S. L., Barrero, F., Martínez-Torres, M. R., Gallardo, S., \& Lillo, J. (2005). Implementation of a webbased educational tool for digital signal processing teaching using the technological acceptance model. IEEE Transactions on Education, 48(4), 632-641.

Toral, S. L., Martínez-Torres, M. R., Barrero, F., Gallardo, S., Vargas, E., \& Gónzalez, V. (2006). Planning a master's level curriculum according to career space recommendations using concept mapping techniques. International Journal of Technology and Design Education, 16(3), 237-252.

Trochim, W. M. K. (1989). An introduction to concept mapping for planning and evaluation. Evaluation and Program Planning, 12(1), 1-16.

Trochim, W. M. K. (1993). The reliability of concept mapping. Paper presented at the Annual Conference of the American Evaluation Association, Dallas, Texas.

University of Deusto and University of Groningen. (2003). Tuning educational structures in Europe, Final Report Phase One. Edited by Julia González Robert Wagenaar.

University of Deusto and University of Groningen. (2005). Tuning educational structures in Europe II Universities' contribution to the Bologna Process. Edited by Julia González Robert Wagenaar.

Van Neste-Kenny, J., Cragg, C.E., \& Foulds, B. (1998). Using concept maps and visual representations for collaborative curriculum development. Nurse Educator, 23(6), 21-25.

Ward, J. H. (1963). Hierarchical grouping to optimize an objective function. Journal of the American Statistical Association, 58, 236-244. 